\title{
QUIZ ON AIRWAY
}

Azliana $\mathrm{A}^{1}$, Nik Fariza $\mathrm{HNH}^{1,2}$

${ }^{1}$ Department of Otorinolaryngology- Head \& Neck Surgery, School of Medical Sciences, Universiti Sains Malaysia, 16150 Kota Bharu, Kelantan, Malaysia.

${ }^{2}$ Speech Pathology Programme, School of Health Sciences, Universiti Sains Malaysia, 16150 Kota Bharu, Kelantan, Malaysia.

\section{CASE SUMMARY}

A 23-year-old gentleman sustained brain injury after motor-vehicle accident two years ago. He had a tracheostomy during the admission and was decannulated one month later. He recently admitted and had an endotracheal intubation for an elective procedure (non related to airway) performed under general anaesthesia. Intubation was difficult due to his narrow airway. The anaesthetist managed to insert a size 6.0 endotracheal tube after three attempts. He was managed in neuro ICU post procedure and was intubated for four days. Post extubation, he was referred to ORL-HNS for stridor. He complaints of intermittent stridor on exertion. Clinical and endoscopic examinations of the larynx were performed at bedside using flexible nasopharyngolaryngoscope. Subsequently, direct laryngoscopy was performed under general anaesthesia for further management. Below is the endoscopic view of the direct laryngoscopy done under general anaesthesia (Figure 1).

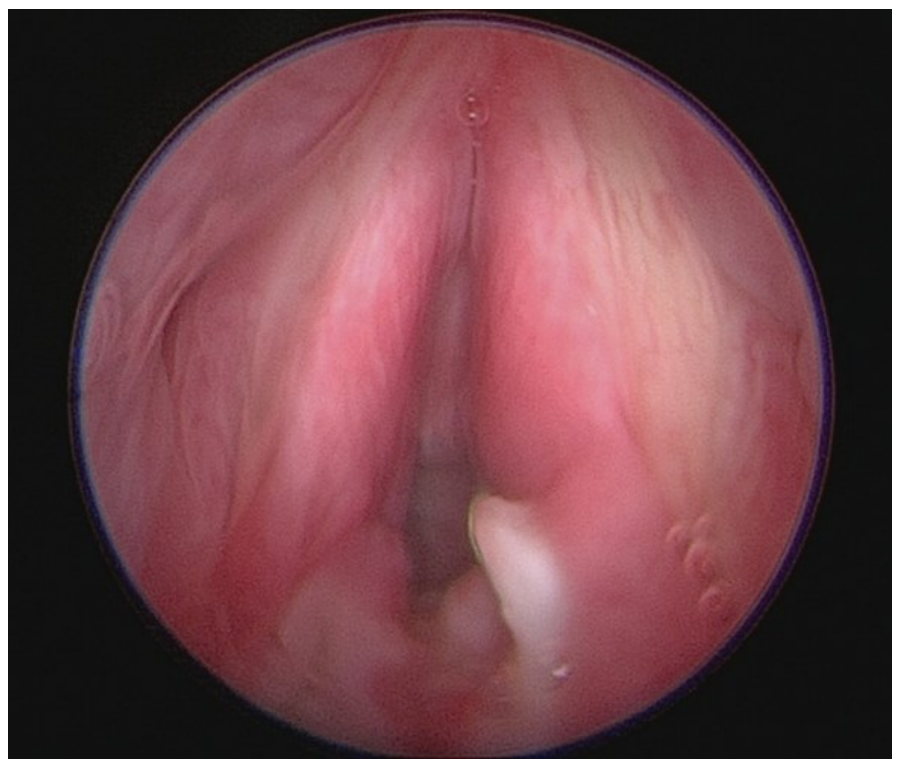

Figure 1: Endoscopic view of the larynx using zero degree endoscope inserted through the direct laryngoscope

Corresponding author:

Azliana Aziz

Department of Otorinolaryngology- Head \&

Neck Surgery,

School of Medical Sciences,

Universiti Sains Malaysia,

16150 Kota Bharu, Kelantan, Malaysia.

Phone: $+6019-4549832$

Email:az.aziz21@yahoo.com

\section{QUESTIONS:}

Q1: State the findings on the endoscopic view and what is the likely cause of stridor?

Q2: How to manage the problem?

(Answer on the next page) 


\section{ANSWERS:}

A1: A significant subchordal oedema is seen and it caused a marked narrowing of glottis. The normal architecture of bilateral vocal cord was seen lateral to the subchordal oedema characterised by yellowich in colour and linear vasculature running on the vocal cords (thin arrow). There was also a well circumscribed mass seen 12 o'clock below the subchordal oedema (double headed arrow), that further contributes to the airway narrowing. A posterior commissure ulcer seen at the interarythenoid mucosa (thick arrow).

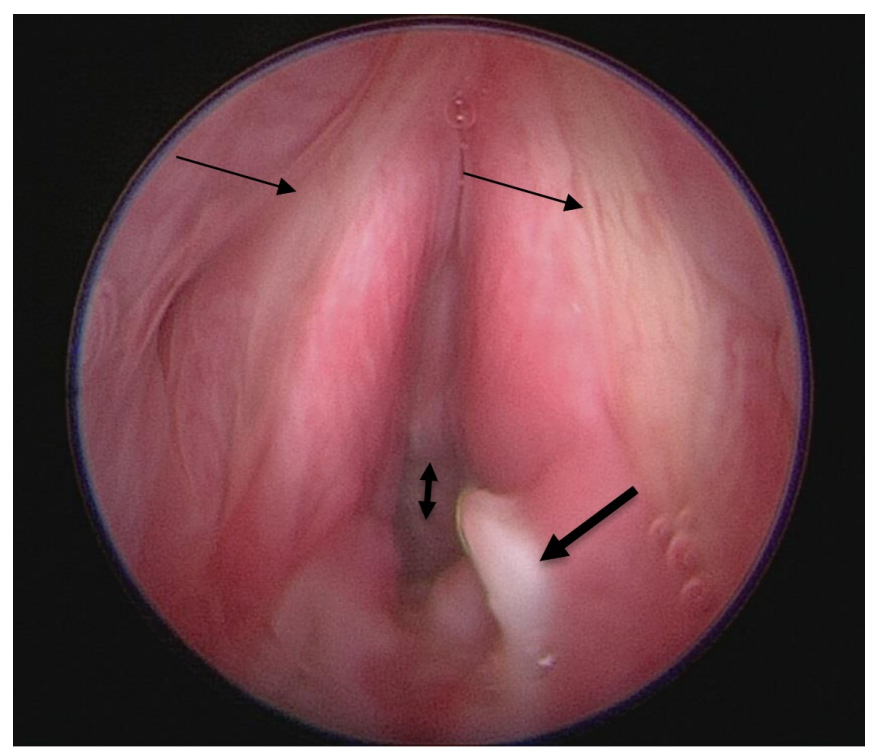

The stridor was likely due to the marked subchordal oedema and the subglottic stenosis.

A2: There are three concomitant problem seen in this endoscopic view; the subchordal oedema, granulation tissue and posterior commissure ulcer.

To give the patient an adequate airway is the utmost priority in managing this patient as there was significant airway stenosis and laryngeal injury. Tracheostomy is the first line management of the patient.

After the airway is secured, the cause of the massive subchordal oedema must be determined and managed accordingly. One of the differential diagnosis is laryngopharyngeal reflux that need to be diagnosed clinically by Reflux Symptoms Index (RSI) 1 and Reflux Finding Score (RFS) 2 then later confirmed with 24 hour double pH study.

For the posterior commissure ulcer, early extubation is the first line treatment. Intralesional steroid and proton pump inhibitor is also an adjuvant treatment of choice.

\section{REFERENCES}

1. Belafsky PC, Postma GN, et al, Validity and reliability of the reflux symptom index (RSI). J Voice. 2002;16:274-7.

2. Belafsky PC, Postma GN, et al, The Validity and Reliability of the Reflux Finding Score (RFS). Laryngoscope, 2001;111: 1313-17. 